\title{
PERANCANGAN PEMUSNAHAN REKAM MEDIS RAWAT JALAN DI PUSKESMAS SERING MEDAN TAHUN 2018
}

\author{
1. Sofyan; ${ }^{2}$ Mei Gemini Sitohang \\ ${ }^{1}$ Dosen APIKES Imelda, Jalan Bilal Nomor 52 Medan; ${ }^{2}$ Alumni APIKES Imelda
}

E-mail: ${ }^{1 .}$ sofyanakademik@gmail.com

\begin{abstract}
ABSTRAK
Puskesmas adalah Fasilitas pelayanan kesehatan yang menyelenggarakan upaya kesehatan masyarakat dan upaya kesehatan perseorangan tingkat pertama dengan lebih mengutamakan upaya promotif dan preventive, untuk mencapai derajat kesehatan masyarakat yang setinggi-tingginya di wilayah kerjanya (RI NO.75 Tahun 2014). Rekam medis berdasarkan Permenkes RI No.269/Menkes/Per/III/2008 merupakan berkas yang berisikan catatan dan dokumen tentang identitas pasien, pemeriksaan, pengobatan, tindakan, dan pelayanan lain yang telah dberikan kepada pasien. Berkas rekam medis pada rak penyimpanan tidak selamanya akan disimpan. Hal ini dikarenakan jumlah rekam medis terus bertambah sehingga ruang penyimpanan akan penuh dan tidak mencukupi lagi untuk rekam medis rekam medis yang baru. Pemusnahan rekam medis merupakan salah satu upaya yang dilakukan oleh pihak puskesmas dengan tujuan mengurangi penumpukan berkas rekam medis diruang penyimpanan.Berkas rekam medis rawat jalan disimpan selama 2 tahun. Jenis penelitian ini menggunakan penelitian deskripsi kualitatif. Penelitian kualitatif merupakan penelitian yang digunakan untuk menyelidiki, menemukan, menggambarkan. Puskesmas sering sudah melakukan pemusnahan terhadap berkas rekam medis dari tahun 1990 sampai dengan tahun 2015 dengan cara dibakar tanpa mengikuti proses yang sesuai dengan permenkes. Pemusnahan seharusnya dilakukan sesuai dengan prosedur PerMenkes. Perlu adanya petugas khusus tamatan rekam medis untuk mengelola rekam medis yang ada di puskesmas.
\end{abstract}

Kata Kunci: Perancangan, Pemusnahan, Rekam Medis, Rawat Jalan.

\section{PENDAHULUAN}

Puskesmas adalah Fasilitas pelayanan kesehatan yang menyelenggarakan upaya kesehatan masyarakat dan upaya kesehatan perseorangan tingkat pertama dengan lebih mengutamakan upaya promotif dan preventi ve, untuk mencapai derajat kesehatan masyarakat yang setinggi-tingginya di wilayah kerjanya (RI NO.75 Tahun 2014). Puskesmas adalah fasilitas pelayanan kesehatan yang menyelenggarakan upaya kesehatan masyarakat dan upaya kesehatan perseorangan tingkat pertama, dengan lebih mengutamakan upaya promotifdan preventif untuk mencapai derajat kesehatan masyarak at yang setinggi-tingginya di wilayah kerjanya (Permenkes No.13 Tahun 2015).

Puskesmas berfungsi sebagai pelayanan kesehatan masyarakat yang lebih mengutam akan pelayanan promotif dan preventif, dengan kelompok masyarakat serta sebagian besar diselengarakan bersama masyarakta yang bertempat tinggal di wilayah kerja puskesmas dan pelayanan medik dasar yang mengutamakan pelayanan kuratif dengan pendekatan individu dan keluarga pada umumnya melalui upaya rawat jalan dan rujukan (DEPKES RI, 2007).

Rekam medis adalah keterangan baik yang tertulis maupun yang terekam tentang identitas, anamneses penentuan fisik laborat orium, diagnose segala pelayanan dan tindakan medic yang diberikan kepada pasien dan pengobatan yang baik yang dirawat inap, rawat jalan maupun yang mendapat pelayanan gawat darurat (Rustiyanto, 2009).

Berkas rekam medis pada rak penyimpa nan tidak selamanya akan disimpan. Berkas 
rekam medis harus disimpan sesuai dengan peraturan yang telah dibuat oleh peraturan UU Permenkes 2008 pasal 09 ayat 01 : Rekam medis pada sarana pelayanan Kesehatan non rumah sakit wajib disimpan sekurang kurangnya waktu jangka 2 tahun terhitung dari tanggal terakhir pasien berobat. Dan Berdasarkan Permenkes 2008 pasal 09 ayat 02: setelah batas watu sebagai mana dimaksud pada ayat 01 dilampaui, rekam medis dapat dimusnahkan. Rekam medis harus disimpan sesuai dengan peraturan yang ada.

Berkas rekam medis harus dimusnahka n, Hai ini dikarenakan jumlah rekam medis di Puskesmas bertambah sehingga ruang penyimpanan akan penuh dan tidak mencukupi lagi untuk rekam medis yang baru. Pemusnahan rekam medis merupakan salah satu upaya yang dilakukan oleh pihak puskesmas dengan tujuan mengurangi penumpukan berkas rekam medis diruang penyimpanan.Pemusnahan adalah kegiatan menghancurkan secara fisik arsip yang sudah berakhir fungsinya serta yang tidak memiliki nilai guna ( Barthos 2007). Sistem pemusnahan berkas rekam medis rawat jalan yang baik perlu diterapkan dalam merancang sistem pemusnahan sehingga mendapatkan hasil yang bermutu.

Berdasarkan survey awal yang telah peneliti lakukan di Puskesmas Sering, ditemukan bahwa Puskesmas sering sudah melakukan sistem pemusnahan pada berkas rekam medis rawat jalan. Di puskesmas Sering berdiri sejak tahun 1990, berkas rekam medis dari tahun 1990sampai 2015 sudah dimusnahkan begitu saja tanpa proses yang benar. Maka dari itu penulis untuk melakukan penelitian dengan berjudul 'Perancangan Sistem Pemusnahan Rekam Medis Rawat Jalan Di Puskesmas Sering Tahun 2018'.

\section{Rumusan Masalah}

1. Bagaimana cara merancang pemusnaha n rekam medis rawat jalan?

2. Apa saja yang dibutuhkan untuk melak ukan pemusnahan ?

3. Kapan dilaksanakan untuk melakukan pemusnahan berkas rekam medis?

\section{Tujuan}

Mengetahui bagaimana pelaksanaan perancangan sistem pemusnahan rekam medis rawat jalan di Puskesmas Sering.

\section{Manfaat Penelitian}

1. Bagi Puskesmas

Sebagai bahan masukkan bagi puskesm as dalam merancang pemusnahan berkas rekam medis di Puskesmas Sering Medan.

2. Bagi Pendidikan

Dapat dijadikan sebagai bahan referensi pustaka yang dipergunakan untuk penelitian selanjutnya.

3. Bagi Penelit

Sebagai bahan perbandingan ilmu yang diperoleh selama pendidikan dengan kenyataan yang ada di lapangan atau tempat penelitian.

\section{METODE}

\section{Jenis Peneltian}

Jenis penelitian ini menggunakan penelitian deskripsi kualitatif. Penelitian kualitatif merupakan penelitian yang diguna kan untuk menyelidiki, menemukan, menggambarkan (Saryono, 2013). Metode yang digunakan yaitu wawancara, pengamat an dan pemanfaatan dokumen rekam medis.

\section{Waktu Penelitian}

Waktu Penelitian di lakukan pada bulan Juli 2018

\section{Tempat Penelitian}

Tempat Penelitian ini dilakukan di Puskesmas Sering yang beralamat di Jl Sering No 20 Kelurahan Sidorejo, Kecamata n Medan Tembung. Alasan memilih tempat penelitian karena belum diadakan pemusnah an rekam medis.

\section{Variabel}

Variabel merupakan segala sesuatu yang berbentuk apa saja yang ditetapkan oleh peneliti untuk dipelajari sehingga diperoleh informasi tentang hal tersebut (sullistyaningsih, 2011). Adapun variablevariabel yang akan diamati oleh peneliti sebagai berikut : 
1. Pemusnahan rekam medis

2. Persiapan pemusnahan

3. Rekam medis inaktif

4. Pemilahan rekam medis
5. Lembar bernilai guna

6. Lembar tidak bernilai guna

7. Sumber Daya Manusia

\section{Defenisi Operasional}

Untuk membatasi ruang lingkup atau pengertian variable-variabel tersebut diberi batasan atau definisi operasional (Notoatmodjo, 2012.

Tabel 1. Definisi Operasional

\begin{tabular}{|c|c|c|}
\hline No & Variabel & Defenisi Operasional \\
\hline 1. & $\begin{array}{l}\text { Pemusnahan } \\
\text { medis }\end{array}$ & $\begin{array}{l}\text { Adalah suatu tindakan atau kegiatan menghancurkan secara } \\
\text { fisik arsip yang sudah berakhir fungsinya serta yang tidak } \\
\text { memiliki nilai guna }\end{array}$ \\
\hline 2. & Persiapan pemusnahan & $\begin{array}{l}\text { Adalah kegiatan menilai dan memilah berkas rekam medis } \\
\text { yang sudah tidak bernilai guna }\end{array}$ \\
\hline 3. & Rekam medis inaktif & $\begin{array}{l}\text { Adalah rekam medis yang tidak digunakan lagi sejak } \\
\text { kunjungan terakhir pasien atau frekuensi kunjungannya } \\
\text { berkurang dalam kegiatan penyelenggaraan. }\end{array}$ \\
\hline 4. & Penilaian rekam medis & $\begin{array}{l}\text { Adalah menilai lembar-lembar rekam medis yang masih } \\
\text { mempunyai nilai guna dan tidak mempunyai nilai guna }\end{array}$ \\
\hline & Pemilahan & $\begin{array}{l}\text { Adalah memilah antara lembar bernilai guna dan lembar } \\
\text { tidak bernilai guna }\end{array}$ \\
\hline 6. & Lembar bernilai guna & $\begin{array}{l}\text { Adalah lembar yang masih mempunyai kegunaan untuk } \\
\text { administrasi hokum, keuangan. Iptek, pembuktian dan } \\
\text { sejarah }\end{array}$ \\
\hline & $\begin{array}{l}\text { Lembar tidak bernilai } \\
\text { guna }\end{array}$ & Adalah Lembar yang sudah tidak bernilai guna lagi \\
\hline & $\begin{array}{l}\text { Sumber daya manusia } \\
(\mathrm{SDM})\end{array}$ & Adalah orang yang mengerjakan persiapan pemusnahan \\
\hline & Fasilitas & $\begin{array}{l}\text { Adalah alat-alat yang digunakan untuk melakukan } \\
\text { persiapan pemusnahan meliputi tempat pemusnahan, alat } \\
\text { pencacah Dan komputer }\end{array}$ \\
\hline
\end{tabular}

\section{Jenis data penelitian}

1. Data Primer yaitu data yang diperoleh langsung dari subjek penelitian dengan menggunakan alat pengukur atau alat pengambilan data, langsung pada subjek sebagai informasi yang dicari (Suryono,2013)

2. Data Sekunder yaitu data Yang diperoleh dari pihak lain, tidak langsung diperoleh oleh peneliti dari subjek penelitiannya (Suryono,2013)

\section{Instrumen Penelitian}

Instrumen penelitian adalah alat atau fasilitas yang digunakan oleh peneliti dalam mengumpulkan data agar pekerjaannya lebih mudah dan hasilnya lebih baik (Arikunto,
2010). Instrumen yang digunakan dalam penelitian adalah :

a. Check-List Observasi

Check list adalah suatu daftar pengecek, berisi nama subjek dan beberapa gejala/identitas lainnya dari sasaran pengamatan.pengamat tinggal memberikan tanda check (x) pada daftar tersebut menunjukkan adanya gejala/cirri dan sasaran pengamatan (Notoatmodjo, 2012). Check list dalam penelitian ini berisi hal-hal yang diamati, meliputi fasilitas pemusnahan, lembar-lembar yang dipilah.

b. Pedoman wawancara

Pedoman wawancara ini berisi daftar pertanyaan yang akan diajukan oleh 
peneliti kepada subjek penelitian terkait persiapan pemusnahan

c. Alat tulis

Alat tulis pada penelitian ini adalah pena dan buku yang digunakan untuk mencatat hasil penelitian.

d. Alat perekam (recording)

Alat perekam digunakan untuk merekam hasil wawancara. Dalam hal ini penelti menggunakan HP untuk merekam hasil wawancara.

\section{Cara Pengumpulan Data}

a. Wawancara (interview)

Wawancara merupakan suatu metode yang digunakan untuk mengumpulkan data, dimana peneliti mendapatkan keterangan atau pendirian secara lisan dari sasaran penelitian (responden) atau bercakap-cakap berhadapan dmuka dengan orang tersebut (Notoatmojo,2012)

b. Pengamatan (observasi)

Pengamatan ini dilakukan untuk mendapatkan data sekunder yang dilakukan dengan cara mencatat, mempertimbangkan dan memberikan penelitian dengan melakukan pengamatan langsung terhadap apa yang diteliti, Observasi yang dilakukan adalah mewawancarai ada atau tidaknya perancangan pemusnahan pada berkas rekam medis.

\section{HASIL}

Berdasarkan hasil penelitian Di Puskesmas Sering diketahui bahwa Puskesmas Sering mempunyai 3 rak penyimpanan berkas rekam medis. Ketiga rak penyimpanan tersebut berfungsi untuk menyimpan berkas rekam medis aktif. Ketiga rak berada di belakang tempat pendaftaran. Puskesmas Sering tidak mempunyai ruang penyimpanan khusus untuk berkas rekam medis yang in-aktif.

Berkas rekam medis dari tahun 1990 sampai dengan tahun 2015 sudah dimusnahkan oleh petugas Puskesmas Sering dengan cara dibakar karena berkas rekam medis tersebut sudah rusak secara biologis (rayap) dan tidak terbaca. Semua berkam rekam medis dimusnahkan tanpa mengkategorikan suatu penyakit. Berkas rekam medis yang masih disimpan di dadalam rak penyimpanan yaitu berkas tahun 2015 sampai 2018.

Tabel 2. Standar Operasional Prosedur Di Puskesmas Sering Tahun 2018

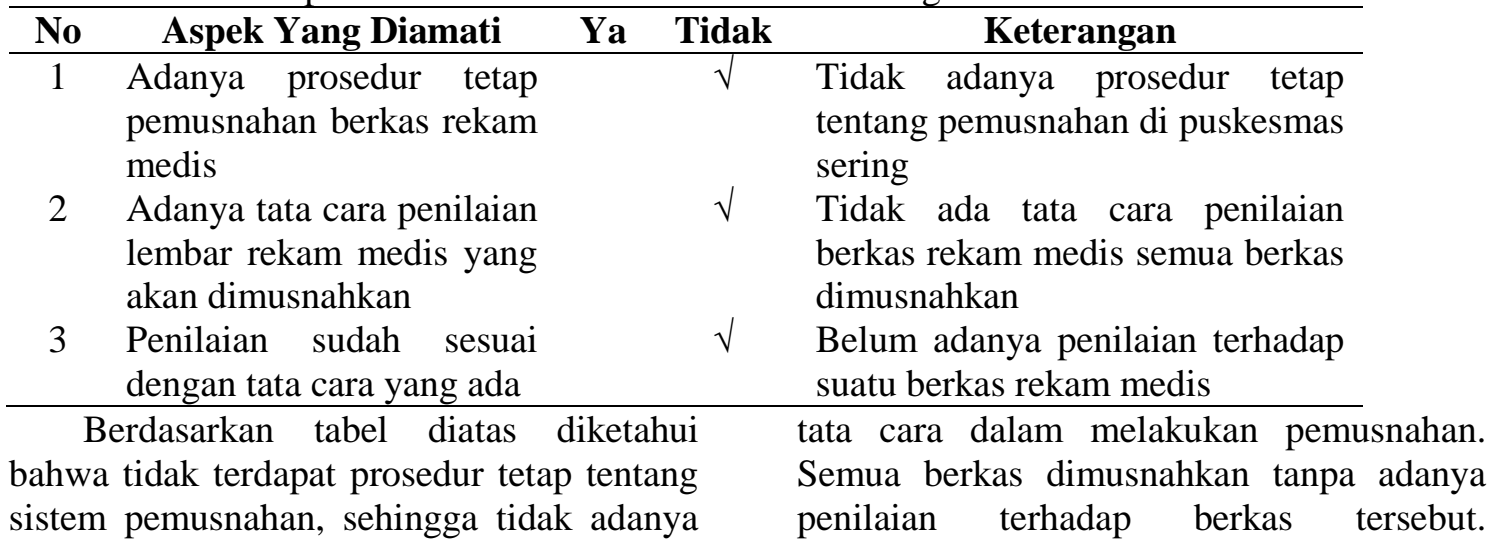

Tabel 3. Lembar Rekam Medis Di Puskesmas Sering Tahun 2018

\begin{tabular}{clclc}
\hline No & \multicolumn{1}{c}{ Aspek Yang Diamati } & Ya & Tidak & Keterangan \\
\hline 1 & Adanya lembar resume & $\sqrt{ }$ & - & Dimusnahkan \\
\hline 3 & Adanya lembar persetujuan & $\sqrt{ }$ & - & Dimusnahkan \\
\hline 4 & Adanya lembar identifikasi bayi & $\sqrt{ }$ & - & Dimusnahkan \\
\hline 5 & Adanya lembar rujukan & $\sqrt{ }$ & - & Dimusnahkan \\
\hline 6 & Adanya lembar pengkajian perawatan & $\sqrt{ }$ & - & Dimusnahkan \\
\hline 7 & $\begin{array}{l}\text { Adanya lembar catatan } \\
\text { perkembangan }\end{array}$ & $\sqrt{ }$ & - & Dimusnahkan \\
\hline 8 & Adanya persetujuan di rawat inap & $\sqrt{ }$ & - & Dimusnahkan \\
\hline
\end{tabular}




\begin{tabular}{|c|c|}
\hline 9 & 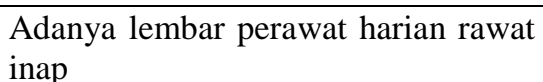 \\
\hline 10 & 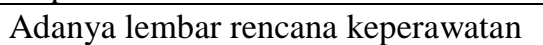 \\
\hline 11 & $\begin{array}{r}\text { le } \\
\text { kep }\end{array}$ \\
\hline 12 & \\
\hline & \\
\hline \multicolumn{2}{|c|}{$\begin{array}{l}\text { Berdasarkan tabel } 3 \text { diatas bahwa hasi } \\
\text { ervasi bahwa seluruh berkas rekam } \\
\text { dis dimusnahkan oleh petugas rekam } \\
\text { dis di Puskesmas Sering tidak adanya } \\
\text { nilahan terhadap berkas yang harus } \\
\text { usnahkan. }\end{array}$} \\
\hline
\end{tabular}

\section{PEMBAHASAN}

Berdasarkan hasil wawancara terhadap petugas di Puskesmas Sering sudah dilakukan pemusnahan terhadap berkas rekam medis namun belum sesuai dengan sistem pemusnahan menurut Permenkes RI No.269/Menkes/Per/III/2008, karena semua berkas dimusnahkan dengan cara dibakar tanpa dipilah menurut tahun terakhir kunjungan dan kategori suatu penyakit. Pelaksanaan melakukan pemusnahan rekam medis yang ada Di Puskesmas Sering dikumpul seluruh petugas puskesmas, lalu dibicarakan ketepatan mulai tahun berapa retensi akan dilakukan, dibuat tim penilai, pelaksanaan pemusnahan dan disiapkan berita acara agar melakukan pemusnahan berkas rekam medis.

Pemusnahan rekam medis inaktif fungsinya untuk menghancurkan secara fisik yang sudah berakhir yang tidak memiliki nilai guna terhdap berkas rekam medis. Adapun tata cara dalam melakukan pemusnahan berkas rekam medis yang baik yaitu

Pembakaran dengan cara dibakar habis, Pencacahan (Pencacah yang menggunakan alat mesin sehingga dokumen berkas rekam medis terpotong-potong dan tidak bisa dikenali lagi), Proses kimiawi (bahan kimia yang melenyapkan tulisan) dan Pembuburan atau pulping (dokumen yang akan dimusnahkan dengan air kemudian dicacah dan disaring yang akan menghasilkan lapisan bubur kertas. Dalam tata cara cara pemusnahan yang baik dilakukan untuk mengurangi berkas rekam medis pada rak penyimpanan. ( Wahyono,
Dimusnahkan

Dimusnahkan

Dimusnahkan

Dimusnahkan

Dimusnahkan

2005). Tim-tim yang ikut dalam melakukan pemusnahan rekam medis ialah Kepala Puskesmas, Dokter, Perawat serta bila perlu adanya tenaga rekam medis.

Dalam melakukan tahapan-tahapan pemusnahan di Puskesmas Sering seharusn ya mengikuti suatu prosedur yang ditetapkan

dalam PERMENKES RI No 269Menkes/Pe r/III/2008, yaitu

1) Dilihat dari tanggal kunjungan terakhir.

2) Berkas rekam medis pasien yang tidak pernah berkunjung lagi ke puskesmas selama 5 tahun secara berturut-turut maka rekam medisnya dinyatakan inaktif.

3) Berkas rekam medis inaktif dikelompo kkan sesuai dengan tahun terahir kunju ngan.

4) Berkas rekam medis tertentu disimpan di inaktif misalnya seperti resume, lembar identifikasi bayi lahir hidup, lembar persetujuan, lembar kematian dan hasil pemeriksaan yang penting.

5) Lembar berkas rekam medis yang rusak atau tidak terbaca disiapkan untuk dimusnahkan.

6) Tim pemusnah dibentuk dengan Surat Keterangan (SK) Kepala Puskesmas yang beranggotakan panitia rekam medis, perawat senior dan tenaga lain yang terkait.

7) Pelaksanaan pemusnahan secara dicacah, dibakar, proses kimiawi, pembuburan atau pulping.

8) Tim pemusnah harus membuat berita acara pemusnahan.

9) Berkas rekam medis rawat jalan disimpan selama 2 tahun.

Maka dari itu Sistem Pemusnahan yang sudah diterapkan harus sesuai dengan prosedur tetap, agar berkas rekam medis di Puskesmas Sering berjalan dengan baik. 


\section{KESIMPULAN}

Berdasarkan penelitian yang berjudul "Perancangan Sistem Pemusnahan Rekam Medis Rawat Jalan Di Puskesmas Sering Tahun 2018" yang telah disajikan di Bab IV dapat dismpulkan bahwa :

Puskesmas Sering sudah melakukan pemusnahan terhadap berkas rekam medis dari tahun 1990 sampai dengan tahun 2015 dengan cara dibakar tanpa mengikuti prosedur yang sesuai dengan Permenkes No.269/MENKES 2008. Berkas rekam medis yang ada di Puskesmas Sering yaitu berkas dari tahun 2015 sampai 2018. Berkas yang inaktif harus melakukan pemusnahan rekam medis dalam jangka waktu yang ditetapkan dalam UU Permenkes 2008 pasal ayat 01 .

\section{SARAN}

1. Pemusnahan seharusnya dilakukan sesuai dengan Prosedur yang telah dibuat oleh Permenkes No.269/MENKES/PER/III/2008

2. Bagi Kepala Puskesmas sebaiknya memberikan pengarahan kepada petugas puskesmas agar diterapkan penggunaan pemusnahan rekam medis Di Puskesmas Sering

3. Perlu adanya petugas khusus tamatan rekam medis untuk mengelola rekam medis yang ada di puskesmas.

\section{DAFTAR PUSTAKA}

Arikunto. (2010). Prosedur Penelitian Suatu Pendekatan Praktik. Jakarta: Rineka Cipta.

Barthos. (2007). Pemusnahan Rekam Medis Inaktif. Yogyakarta: Graha Ilmu.

Depkes RI Dirjen Pelayanan Medik. 2006. Pedoman Pengelolaan Rekam Medis Rumah Sakit Indonesia. Jakarta: Departemen Kesehatan Republik Indonesia Direktorat Jendral Pelayanan Medik.

Depkes RI. (1997). Penyusutan Rekam Medis. Jakarta: Departemen Kesehatan Republik Indonesia.

Hatta. (2014). Pedoman Manajemen Informasi Kesehatan di Sarana Pelayanan Kesehatan. Jakarta: Universitas Indonesia.

Menteri Kesehatan. (2014). Puskesmas. Pemerintahan Republik Indonesia. Menkes.

Notoatmodjo. (2012). Pengembangan Sumber Daya Manussia. Jakarta: Rineka Cipta.

Pemerintahan Mentri Kesehatan. (2015). Tentang Puskesmas. Menkes.

Permenkes

No. 269/Menkes/PER/III.(2008). Tentang Rekam Medis.Jakarta: Departemen Kesehatan Republik Indonesia

Sulystianingsih. (2011). Metodologi Penelitian Kebidanan KuantitatifKualitatif. Yogyakarta: Graha Ilmu.

Saryono. (2013). Metodologi Penelitian Kualitatif dan Kuantitatif Dalam Bidang Kesehatan. Yogyakarta: Nuha Medika. 